\title{
Predicting the performance of cosmopolitan species: dynamic energy budget model skill drops across large spatial scales
}

\author{
Monaco Cristián J. ${ }^{1,{ }^{*}}$, Porporato Erika M. D. ${ }^{2}$, Lathlean Justin A. ${ }^{3}$, Tagliarolo Morgana ${ }^{1,4}$, \\ Sarà Gianluca ${ }^{5}$, McQuaid Christopher D.
}

${ }^{1}$ Department of Zoology and Entomology, Rhodes University, Grahamstown 6140, South Africa

2 Department of Environmental Sciences, Informatics and Statistics, Ca' Foscari University of Venice, 30170 Venice Mestre, Italy

${ }^{3}$ School of Biological Sciences, Queen's University Belfast, Belfast BT7 1NN, UK

${ }^{4}$ UMSR LEEISA (CNRS, UG, Ifremer), Cayenne, French Guiana

${ }^{5}$ Dipartimento di Scienze della Terra e del Mare, University of Palermo, Palermo 90128, Italy

*Corresponding author : Cristián J. Monaco, email address : cristianmonaco@gmail.com

\begin{abstract}
:
Individual-based models are increasingly used by marine ecologists to predict species responses to environmental change on a mechanistic basis. Dynamic Energy Budget (DEB) models allow the simulation of physiological processes (maintenance, growth, reproduction) in response to variability in environmental drivers. High levels of computational capacity and remote-sensing technologies provide an opportunity to apply existing DEB models across global spatial scales. To do so, however, we must first test the assumption of stationarity, i.e., that parameter values estimated for populations in one location/time are valid for populations elsewhere. Using a validated DEB model parameterized for the cosmopolitan intertidal mussel Mytilus galloprovincialis, we ran growth simulations for native, Mediterranean Sea, populations and non-native, South African populations. The model performed well for native populations, but overestimated growth for non-native ones. Overestimations suggest that: (1) unaccounted variables may keep the physiological performance of non-native $M$. galloprovincialis in check, and/or (2) phenotypic plasticity or local adaptation could modulate responses under different environmental conditions. The study shows that stationary mechanistic models that aim to describe dynamics in complex physiological processes should be treated carefully when implemented across large spatial scales. Instead, we suggest placing the necessary effort into identifying the nuances that result in non-stationarity and explicitly accounting for them in geographic-scale mechanistic models.
\end{abstract}


39 Acknowledgements This research was funded by the South African Research Chairs

40 Initiative of the Department of Science and Technology and the National Research

41 Foundation to CDM, and the Italian Minister of University and Research (PRIN TETRIS 2010,

42 grant no. 2010PBMAXP_003) to GS. CJM and MT were supported by a Rhodes University

43 post-doctoral fellowship. The Group for High Resolution Sea Surface Temperature (GHRSST)

44 Multi-scale Ultra-high Resolution (MUR) SST data were obtained from the NASA EOSDIS

45 Physical Oceanography Distributed Active Archive Center (PO.DAAC) at the Jet Propulsion

46 Laboratory, Pasadena, CA (http://dx.doi.org/10.5067/GHGMR-4FJ01). Chlorophyll-a data

47 were generated using CMEMS Products, production centre ACRI-ST. We thank Jaqui 
Trassierra for assistance during fieldwork. An anonymous reviewer and the Associate Editor, Sandra Shumway, provided insightful comments that improved our manuscript.

50

\section{Introduction}

52 Understanding and predicting species' responses to environmental variability requires careful consideration of individual-level physiological processes (Kearney 2006; Denny and Helmuth 2009; Monaco and Helmuth 2011). Individual-based energy budget models offer an opportunity to make mechanistic links between environmental drivers and the ecological success of species in both natural and altered systems (Hochachka and Somero 2002). The main strength of such mechanistic models, as opposed to the more widely applied statistical models (e.g. species distribution correlative models), is an explicit focus on the organism's fundamental niche. The more process-based nature of this approach implies no assumptions about the influence of locally contingent factors (e.g. biotic interactions) on species baseline responses, and therefore holds greater potential for reliably anticipating dynamics in a species' performance and distribution (Kearney 2006). Different types of energy budget models exist, varying in degree of generality, sophistication, or theoretical justification (Karasov and Martínez del Rio 2007). Depending on the investigator's research goals, these models can be as complex as desired. For example, energy budget models have been constructed to account for gradients in single or

67 multiple stressors that can be either biotic or abiotic (Branch 1981; Widdows and Johnson 1988; Hölker and Mehner 2005; Kitazawa et al. 2008; Sokolova 2013), and can incorporate behaviour (e.g. microhabitat use for regulating body temperature, Grant and Porter 1992). Indeed, thorough descriptions of the ecological and physiological context are increasingly favoured in mechanistic studies (Denny and Helmuth 2009; Pincebourde and Woods 2012; 
Potter et al. 2013). Simultaneously, given the global scale of some of the challenges facing species today (e.g. climate change) and the growing number of species exhibiting shifting or expanding distribution limits, notably, invasive species (Walther et al. 2002; Seebens et al. 2017), there is a pressing need for accurate models that can be implemented at both local and global scales. Ideally, models should therefore strive to balance the contextdependence of physiological performance, without compromising the power to describe the larger scale processes that may ultimately define the ecological performance of the species. While technological bottlenecks prevented the application of individual-based models across large spatial scales in the past, advances in remote sensing technology and computational power provide today's marine biologists with access to large-scale environmental data, and allow the rapid performance of the necessary calculations (Kerr and Ostrovsky 2003; Hofmann and Gaines 2008). It is now possible for energy budget models to describe and project the physiological condition of species across their entire distributional range.

Importantly, however, for many existing mathematical models to be applicable across space, we must assume 'spatial stationarity', i.e. that parameter values estimated for populations in one location/time are valid for populations elsewhere (Stenseth et al. 2003; Woodin et al. 2013; Montalto et al. 2015). The assumption of model stationarity has been challenged extensively in the literature on species distribution models (i.e. correlative modelling), and innovative solutions have been proposed. For instance, instead of assuming fixed regression coefficients for the whole distribution of their species, Kupfer and Farris (2007) relied on geographically weighted regression models that are flexible/adaptive across space. Such flexibility was also embraced by Hothorn et al. (2011), using a method that decomposes the variability of local and global effects of environmental drivers to produce 
statistical models that can deal with not only non-stationarity, but also spatiotemporal autocorrelation. While such implementations can incorporate non-stationarity, these solutions still suffer from the drawbacks of species distribution models: they are grounded on statistical approximations that describe relationships, often neglecting cause-effect mechanisms. Unfortunately, however, predictive mechanistic models put forward by physiological ecologists rarely test the stationarity assumption, and few attempts have been made to account for non-stationarity in parameter values (for exceptions see Buckley 2008; Alunno-Bruscia et al. 2011). For energy budget models, this implies that parameter values defining flow of energy through an individual are constant. Because phenotypic plasticity and local adaptation are pervasive in nature (Sanford and Kelly 2011; Valladares et al. 2014), regarding species as uniform entities is probably incorrect. Thus, for energy budget models to be useful at all spatial scales, we must first test the assumption of stationarity. Here we examine stationarity in a Dynamic Energy Budget (DEB) model (Kooijman 2010) developed for the Mediterranean mussel Mytilus galloprovincialis. We choose to use DEB modelling due to its growing popularity among ecologists owing to its ability to model underlying physiological processes (growth, reproduction, and maintenance) based on first principles that are applicable across different taxa and ontogenetic stages (Sousa et al. 2010; Monaco et al. 2014). DEB models also have the advantage of being able to accommodate temporal/spatial variability in environmental drivers such as temperature, food availability (Saraiva et al. 2011), and pH (Klok et al. 2014), all of which are predicted to vary at a global scale with climate change. We worked with $M$. galloprovincialis because, as a cosmopolitan species present on all continents except Antarctica, this mussel offers the chance to compare the model's performance across very large (inter-hemispheric) geographical scales. Additionally, because M. galloprovincialis is such a successful invasive 
species, evaluating its physiological performance at non-native sites could improve our

121 understanding of its spread and impact on natural systems.

122 Although DEB theory has existed for over 35 years and its utility has been widely confirmed by virtue of the many species already parameterized (van der Meer et al. 2014),

124 its application to model species, including M. galloprovincialis, is mostly constrained to very 125 local spatial scales (but see Tagliarolo et al. 2016). DEB models are generally parameterized 126 based on real data collected from few populations, and plasticity in traits is often ignored,

127 i.e. stationarity is assumed. Given the rapid progress in DEB theory and the prospect of 128 applying it to large spatial scales in applied and exploratory research (Alunno-Bruscia et al. 129 2011; Montalto et al. 2015), testing the assumption of stationarity thus becomes an 130 imperative. This study tests the stationarity assumption by comparing the ability of a DEB model

132 to predict size-at-age for individuals collected from Mediterranean Sea native sites, for which we develop the model (control region), and South African non-native sites.

134 Anticipating possible non-stationarity, we explored variability in the two main driving 135 variables, temperature and food availability, in relation to the model's skill. Finally, in light 136 of these environmental data, we examine and discuss possible ways to incorporate non-

137 stationarity in key DEB model parameters to obtain better predictions for non-native 138 regions.

Materials and methods

\section{Study regions and sites}

142 Mytilus galloprovincialis is a cosmopolitan species spread across temperate rocky shores in 143 both hemispheres. Here we focused on two regions, the European coast of the 
Mediterranean Sea (Italy), and the southern tip of Africa (South Africa) (Fig. 1A). M.

146 parameterized based on populations from that region, specifically located in the Gulf of

147 Castellammare $\left(38^{\circ} 02^{\prime} 26.9^{\prime \prime} N, 12^{\circ} 55^{\prime} 18.5^{\prime \prime}\right.$ E) (Sarà et al. 2012). Here we sampled four

148 intertidal Italian populations that were different from those used by Sarà et al. (2012) to

149 develop the original model: Gaeta $\left(41^{\circ} 13^{\prime} 00.7^{\prime \prime} \mathrm{N}, 13^{\circ} 32^{\prime} 02.9^{\prime \prime} \mathrm{E}\right)$, Otranto $\left(40^{\circ} 08^{\prime} 38.0^{\prime \prime} \mathrm{N}\right.$,

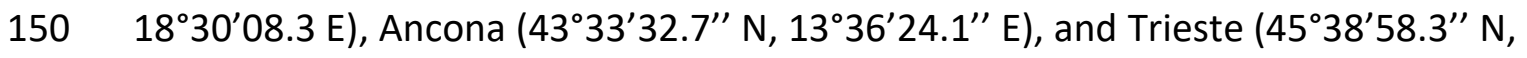

$15113^{\circ} 46^{\prime} 36.5^{\prime \prime}$ E) (Fig. 1B), which were used for quality control of the performance of the

152 existing DEB model. To test the current model under conditions experienced by mussels in a

153 non-native region, we used four intertidal South African populations: Hondeklip Bay

$154\left(20^{\circ} 18^{\prime} 19.2^{\prime \prime} \mathrm{S}, 17^{\circ} 16^{\prime} 18.5^{\prime \prime} \mathrm{E}\right)$, Paternoster ( $\left.32^{\circ} 48^{\prime} 44.3^{\prime \prime} \mathrm{S}, 17^{\circ} 52^{\prime} 48.8^{\prime \prime} \mathrm{E}\right)$, Brenton-on-sea

$155\left(34^{\circ} 04^{\prime} 31.1^{\prime \prime} \mathrm{S}, 23^{\circ} 01^{\prime} 26.1^{\prime \prime} \mathrm{E}\right)$, and St. Francis ( $\left.34^{\circ} 12^{\prime} 30.5^{\prime \prime} \mathrm{S}, 24^{\circ} 50^{\prime} 00.6^{\prime \prime} \mathrm{E}\right)$ (Fig. 1C).

156 Important differences in wave height and tidal range exist between the regions and can

157 presumably influence the degree of mussel submergence and body temperatures. On

158 average, the Mediterranean experiences negligible tidal fluctuations, while the tidal range in

159 South Africa is c. $2 \mathrm{~m}$. Food availability in the form of primary production also differs

160 significantly between the studied sites. The Mediterranean Sea is characteristically

161 oligotrophic (Colella et al. 2016), and the west coast of South Africa, where two of our four

162 sites occur, exhibits higher productivity due to frequent upwelling than the south coast,

163 where the other two sites occur (Brown 1992; Bustamante et al. 1995).

\section{Mussel size-at-age determination}

166 At each of our sites (Fig. 1) we collected animals to determine size-at-age. Italian and South

167 African sites were sampled on July 2013 and August 2014, respectively. The earlier study 

covered the period 2006-2009 (Sarà et al. 2012). We sampled the lower section of mussel beds by collecting all individuals within each of three randomly placed quadrats of $20 \times 20$ $\mathrm{cm}$. Mussels were fixed in $70 \%$ ethanol and transported to the laboratory where shell

172 length, soft tissue dry weight (gonads and soma separated), and age were recorded for each

173 individual. Age was estimated by cutting the shell with a rotary disk and counting the

174 number of annual rings under a stereomicroscope (Peharda et al. 2011; Sarà et al. 2013).

175 The age-length relationship obtained with this method was compared with previous studies

176 done in the same area using several different methods and the results were comparable

177 (Kaehler and McQuaid 1999; McQuaid and Lindsay 2000). Shell length was measured using 178 callipers $( \pm 1 \mathrm{~mm})$.

In this study we used all mussels from the quadrats that were estimated to be 1 or 2 years old. Because mussels were collected from random quadrats, the number of individuals reaching 1 and 2 y was unbalanced among sites and between regions.

\section{DEB model and original parameter values}

Using the DEB model, we simulated mussel growth, in terms of soma dry weight, from birth to age 1 and $2 y$ at all our sites. Predictions were then compared with the observed size (see Mussel size-at-age determination).

Here, we briefly refer to the fundamentals of the DEB model and the main components that allowed testing of the stationarity assumption. More detailed descriptions are given in Kooijman (2010), Sarà et al. (2013), and Monaco and McQuaid (2018). We used a 'standard DEB model' (i.e. one reserve compartment, one structure compartment,

191 isomorphic growth). Food, measured as chlorophyll-a concentration (a proxy for 
phytoplankton concentration in the water), enters the organism's body following a Type II

193 functional response model dependent on a half-saturation coefficient $\left(X_{\kappa}\right)$ (Holling 1959).

194 Assimilated energy is stored in a reserve pool, from which it is allocated according to the $\kappa$ -

195 rule; a fixed proportion (к) goes to maintenance of somatic tissues and growth of structure,

196 while the rest $(1-\kappa)$ is used for maintenance of maturity level and maturation (or gamete

197 production in adults). The rates of all energy flows are modulated by a thermal sensitivity

198 model that describes a typical negatively skewed curve, with zero values marking the

199 temperature tolerance range, and highest values at the temperature at which rates are at

200 maximum values. The chief parameter here, controlling thermal sensitivity within the thermal-tolerance range, is the Arrhenius temperature $\left(T_{A}\right)$. These and other parameters (Appendix S1 in Supporting Information) directly or indirectly influence growth (Kooijman 2010; Sarà et al. 2013; Monaco et al. 2014).

\section{Driving variables: temperature, food availability, and tidal height}

For intertidal mussels, both body temperature and food ingestion vary with the tidal cycle.

To account for this in our model simulations, we included tidal height as a modulating variable. When the tidal height was below the shore level of the mussel bed, feeding was suspended and all temperature-dependent physiological processes were stalled on the basis of metabolic depression (Anestis et al. 2007; Tagliarolo and McQuaid 2015; Monaco and McQuaid 2018). To identify emersion/immersion periods in South Africa, we used tidal height values estimated for each site by the prediction software Marées dans le monde 4.00

213 (StrassGrauerMarina Softwares), and body temperature data logged by 3 biomimetic sensors or "robomussels" deployed between June 2014 and January 2015 at each site (Helmuth et al. 2016). The height on the shore was identified by a sharp drop in 
temperature of $\geq 3^{\circ} \mathrm{C}$ in 30 min during summer following Harley and Helmuth (2003) and comparison with tide tables. The effective shore level ( $m$ above MLLW) for each site was determined by averaging the height on the shore estimated over 20 days (Hondeklip Bay = $0.77 \mathrm{~m}$; Paternoster $=0.72 \mathrm{~m} ;$ Brenton-on-sea $=0.72 \mathrm{~m}$; Saint Francis $=0.72 \mathrm{~m}$ ). Because waves are important at South African sites, a buffer zone of $+0.3 \mathrm{~m}$ was added to this estimated tidal height to ensure temperature readings represented periods when loggers were completely submerged at high tide. For Italian sites, periods of emersion/immersion were identified based on empirical observations of water level and the same tidal prediction software $($ Gaeta $=0.1 \mathrm{~m} ;$ Otranto $=0.15 \mathrm{~m} ;$ Ancona $=0.25 ;$ Trieste $=0.3 \mathrm{~m})$. The DEB model was run for each site using estimated body temperature (derived from Sea Surface Temperature [SST] and air temperature) and chlorophyll-a data as driving variables. Time series of daily SST and concentration of chlorophyll-a, both at processing Level 4 (i.e. spatially gridded and continuous over the time period analysed), were extracted for the years 2011-2014 for all of our sites (Fig. 1) via the R packages raster (Hijmans 2016) and ncdf4 (Pierce 2015) (R Core Team 2016). Air temperature data were extracted from

Weather Underground's API, accessed via the R package rwunderground (https://github.com/ALShum/rwunderground). Time series of daily SST were obtained from the "Group for High Resolution Sea Surface Temperature" (GHRSST - NASA; JPL MUR MEaSUREs Project, 2010) produced using wavelets as basis functions through an optimal interpolation, with a spatial resolution of $0.011^{\circ}$ grid $(\approx 1 \mathrm{~km})$. Data were obtained from numerous instruments, such as the NASA Advanced Microwave Scanning Radiometer-EOS (AMSRE), the Moderate Resolution Imaging Spectroradiometer (MODIS) on the NASA Aqua and Terra platforms, the US Navy microwave WindSat radiometer and in situ SST observations from the NOAA iQuam project. 
241 often ineffective at capturing extremes in intertidal water variability (Lathlean et al. 2011;

242 Smit et al. 2013). For this reason, the satellite-derived SST dataset was ground-truthed

243 using in situ data obtained either from the Italian Oceanographic Buoy Network

244 (Mediterranean Sea sites) or from "robomussels" (South African sites) (Helmuth et al. 2016).

245 In situ SST data were correlated to satellite data to establish site-specific linear relationships

246 (Tagliarolo et al. 2016). The estimated submerged body temperature fed into the DEB

247 models was computed based on these relationships (see Appendix S2 in Supporting

248 Information for linear regression parameters, and S5 for underlying data). Similarly, estimated aerial body temperature was obtained from a relationship between robomussel data and air temperature data computed aggregately for all sites (Appendix S3 and S6).

CMEMS - Ocean monitoring and forecasting service; http://www.myocean.eu/) produced data do not differ significantly from in situ intertidal measurements, at least in the

Mediterranean Sea (Sarà et al. 2011). 
Model predictions of soma dry weight at the end of the simulated periods ( 1 and 2-y old mussels grouped together) were compared against observed size-at-age. First, to assess the magnitude of differences between observations and simulations for each site, we calculated the error statistics Mean Absolute Error (MAE) and Root-Mean Square Error (RMSE).

Second, we compared the model skill between regions and sites using absolute errors.

Because the number of samples was unbalanced (see Mussel size-at-age determination), we conducted bootstrapped ANOVA (Wilcox 2012; Mancuso et al. 2015). The bootstrap involved resampling the data from each region 1000 times and calculating 95\% confidence intervals, which were then contrasted against the critical $F$-value to evaluate statistical differences (Wilcox 2012). Statistical significance was additionally assessed based on the pvalue $(\alpha=0.05)$. The bootstrap ANOVA to test for site effects was followed by a post hoc pairwise comparison with Bonferroni correction.

\section{Results}

\section{Size-at-age observations}

279 Random sampling of mussels provided the necessary 1 and 2-year-old individuals for testing the DEB model. Unfortunately, however, the numbers were unbalanced between ages, 281 sites, and regions (Table 1). between 0.297 (0.093 SD) g for 2-y old mussels in Brenton-on-sea and 0.024 (0.007 SD) g for 1-y old mussels in Gaeta. The difference in mean soma dry weight between 1 and 2-y old mussels was consistently greater for Mediterranean than South African sites (Fig. 2). 
Using DEB model parameters validated for Mediterranean Sea Mytilus galloprovincialis (Appendix S1), we successfully simulated increases in size (soma dry weight) from birth to 1 and 2-y old (Fig. 2). Simulated growth dynamics varied among sites and between regions in response to differences in the driving environmental variables temperature and food availability. For example, growth in the Mediterranean Sea was greater in Ancona and Trieste than Gaeta and Otranto, and generally more pronounced for South African than Mediterranean Sea sites. Growth was similar amongst South African sites despite generally warmer SST on the south (Brenton-on-sea and St. Francis) than the west (Hondeklip Bay and Paternoster) coast. This probably reflects compensation for low temperatures by the much higher chlorophyll levels in the west coast Benguela system, where values can be three times higher than on the south coast (Demarcq et al. 2003; see Model non-stationarity: influence of environmental drivers).

Our assessment yielded no support for model stationarity across the studied regions.

Both error statistics, root mean square error and mean absolute error, revealed a consistently better agreement between observed and predicted soma dry weight for Mediterranean Sea than South African mussel populations (Table 1, Fig. 2-3). This was confirmed by a bootstrapped 1-way ANOVA (Table 2). An effect of site on the model mean absolute error was also detected, and post hoc analysis revealed differences between all sites, expect Brenton-on-sea (South Africa), Ancona, and Trieste (Mediterranean Sea) (Fig. 3).

Model non-stationarity: influence of environmental drivers

310 We found marked differences between regions in the data for the environmental drivers

311 chlorophyll- $a$ and estimated submerged temperature (Fig. 4A-B), but not estimated aerial 
body temperature (Fig. 4C). Variability in mean chlorophyll-a across sites was positively correlated to the model's skill (Fig. 4D), while submerged temperature affected model skill negatively (Fig. 4E). Importantly, while the overall relationships were strong for data pooled for both regions, the regions differed in where they lay along the spectrum of values for both chlorophyll-a and submerged temperature (Fig. 4D-E). The similar mean aerial

317 temperatures experienced by mussels across regions did not correlate with the model's skill 318 (Fig. 4F).

\section{Model non-stationarity: parameter re-estimation}

Since the original DEB model failed to provide good fits for non-native populations, we reestimated some parameters searching for better matches in that region. To narrow the search for candidate parameters, we focused on two physiological processes that are critical for growth, energy intake and thermal sensitivity, which respond to variability in chlorophyll$a$ and temperature respectively. The former is primarily controlled in the model by the halfsaturation coefficient $\left(X_{K}\right)$, and the latter by the Arrhenius temperature $\left(T_{A}\right)$, which is homologous to the more widely utilized $Q_{10}$ (for reference, $T_{A}=6000$ equates to a $Q_{10}$ of 2). A comprehensive grid search allowed us to vary these parameters simultaneously and test the model predictions using 10000 combinations $\left(X_{K}=0.05-5 \mu \mathrm{g} \mathrm{L}-1 ; T_{A}=2080-10000\right.$ $\left.{ }^{\circ} \mathrm{K}\right)$. Predictions improved from a mean absolute error of $0.995 \mathrm{~g}$, when using original parameters, to $0.049 \mathrm{~g}$ when using the parameters that provided the best fit. Despite the improvements, however, the parameter values that minimized the error were extreme $\left(X_{\kappa}=\right.$ $5 \mu \mathrm{g} \mathrm{L}-1 ; T_{A}=10000 \mathrm{~K}$ ) and unrealistic, in comparison to other temperate filter feeder species listed in the DEB add_my_pet collection (http://www.bio.vu.nl/thb/deb/deblab/). Note that this grid search also considered values that matched empirical derivations 
available in the literature. For example, a value of $T_{A}=7090 \mathrm{~K}$ was reported by Tagliarolo and McQuaid (2015) for South African populations of M. galloprovincialis.

\section{Discussion}

340 Climate change is driving dramatic alterations to natural ecosystems through changes in 341 species distributions and by exacerbating the trend of increasing frequency of biological

342 invasions (Walther et al. 2002; Seebens et al. 2017). Anticipating the consequences of these two effects on ecosystem services can be accomplished using mechanistic models that can

344 quantify the physiological condition of native and non-native individuals. A wealth of individual-based models, which can account for aspects of physiology and behaviour, is becoming available (Kearney 2006; Buckley 2013). Because these models capture lifehistory traits that are susceptible to evolution, their parameter values can presumably vary as a function of genetic differentiation (Valladares et al. 2014). Thus, to apply these models across global scales, we must test the assumption of 'stationarity'.

We provide evidence that a standard Dynamic Energy Budget model developed for native, Mediterranean Sea populations of Mytilus galloprovincialis (Sarà et al. 2012) is unable to perform well for non-native, South African populations. We now discuss possible causes of poor performance in DEB models, and then propose ways of moving forward. In general, a model's ability to describe real world processes depends on the estimated parameter values, which in turn are inherently constrained by the number and magnitude of external forces (e.g. environmental drivers) considered during the parameterization stage, as well as physiological constraints imposed by genetics. 
of variability in the two main environmental drivers of mussel physiological performance:

361 temperature (during periods of both aquatic submergence and aerial exposure) and food as

362 expressed by chlorophyll-a. Taking these variables into account, the model predictably

363 provided good fits for the growth of native populations, but overestimated growth for non-

364 native populations. In both regions we strove to describe realistic conditions actually experienced by intertidal mussels by validating SSTs and aerial body temperatures experienced in the field and determining periods of submergence/emergence (Appendices S1-S7). It is important to note, however, that these calculations can only yield rough estimates of the conditions experienced by populations. During aerial exposure, the body temperature of individual ectotherms responds to several weather variables that operate in concert, including not only air temperature but also solar radiation and wind speed

371 (Helmuth 1998). In the absence of direct measurements of body temperatures, our estimates nevertheless captured the expected differences between sites, and thus should serve for large-scale analyses like the one conducted here. possible anaerobic metabolism or oxidative stress incurred by intertidal mussels during prolonged aerial exposure, which can further affect the energy balance of organisms

377 (Anestis et al. 2007; Jimenez et al. 2016; Lesser 2016). Based on recent evidence from 378 Tagliarolo and McQuaid (2015), our model simply assumed metabolic depression during 379 emersion, thus buffering the influence of variable body temperatures in air on energetics and growth. While real mussels probably exhibit initial metabolic depression followed by increased energetic expenditure through the costs of heat shock responses during low tide periods, their exact responses depend on the magnitude, frequency, and duration of thermal/desiccation stress events. Consequently, further empirical work is needed before 
we can integrate these costs into dynamic models like DEB (Gilman 2017). Note, however, that, although we cannot assess how much of that time is spent being splashed vs. fully submerged, the estimated duration of high tide periods was comparable between regions (Mediterranean Sea $=74.9 \%$; South Africa $=78.3 \%$ ). Thus, based on duration alone, failing to consider the extra costs of anaerobiosis would contribute to the model error equally across regions. We also found that similar mean aerial temperatures were experienced by mussels in both regions, suggesting that the effect of temperature on physiological rates during periods of low tide should not differ greatly either. The data presented here suggest that the differences in model skill between regions are more tightly linked to those conditions experienced during high tide periods than low tide events. Indeed, while chlorophyll-a and submerged temperatures were correlated with the model error, aerial temperatures differed little between sites and had no discernible effect on model skill. that other factors that limit energy allocation towards growth were overlooked. First, intertidal mussels in South Africa are often parasitized by endolithic cyanobacteria that cause considerable shell damage, prompting shell repair and increasing the energetic costs of maintenance. These parasites are known to occur in Europe, on the Atlantic coast of Portugal, but both prevalence and intensity of infestation are dramatically lower there (Marquet et al. 2013). Second, wave exposure also increases maintenance costs in mussels, as more energy is directed towards byssal thread production (Carrington 2002; Zardi et al. 2007; Nicastro et al. 2010). Because wave action is much lower in the Mediterranean Sea (Izaguirre et al. 2011), mussels in South Africa sites are again likely to be more energetically constrained (e.g. Zardi et al. 2007). Both of these external factors limit the scope for growth in mussels. That they were not considered in the original DEB model parameterization can 
help explain the model overestimates at non-native sites. Upon entering new systems, nonnative species can both benefit (e.g. increased food, predator/disease release) and suffer

410 (e.g. new enemies, physical stressors) from the new conditions encountered. Our

411 overestimations of growth in non-native sites suggest that the potentially higher

412 physiological performance of M. galloprovincialis in South Africa linked to food availability is

413 kept in check by unaccounted variables such as parasitism and wave action (Nicastro et al.

414 2010; Marquet et al. 2013) that may nullify the advantages of higher chlorophyll concentrations.

The role of genetic variability may also help explain our results. For models seeking

417 to describe physiological processes subject to plasticity and local adaptation, like individual-

418 based energy budget models, model skill is additionally determined by the capacity of the

419 parameters to capture variability in traits across time and space (Woodin et al. 2013;

420 Valladares et al. 2014; Montalto et al. 2015). By comparing populations from vastly

421 different coastlines, our study captured a range of environmental conditions, which $M$.

422 galloprovincialis is necessarily adapted to cope with. The fact that our model can simulate

423 growth for one region but not the other suggests that traits can be flexible. In order to

424 perform well at a global scale, this DEB model needs to incorporate such flexibility in its

425 parameters. The notion that species exhibit phenotypic plasticity and local adaptation has,

426 of course, existed for a long time. Different populations coping with disparate

427 environmental conditions can have different sensitivities to these drivers (Sinervo and

428 Adolph 1994). Little work has, however, been done on the incorporation of genetic

429 variability into predictive models applied across distant populations (but see Buckley 2008).

431 between distant sites have taken two approaches: (1) maintaining parameter values by 

specific conditions (Alunno-Bruscia et al. 2011), i.e. non-stationarity. As a third approach

434 (not discussed here), we could consider independent DEB parameterizations done by separate studies/researchers; however, because these efforts are uncoordinated, their parameter values and predictions are not easily comparable. Our results revealed that the

437 first alternative was not viable for this inter-hemispheric model application. Therefore, we explored the possibility that simple adjustments of parameter values controlling food ingestion $\left(X_{\kappa}\right)$ and temperature sensitivity $\left(T_{A}\right)$ could improve our predictions, offering a 'quick-fix' solution. Alunno-Bruscia et al. (2011) successfully used this approach to model growth and reproduction in the invasive pacific oyster (Crassostrea gigas) collected from different sites with contrasting food quality/quantity conditions along the French coastline. By allowing $X_{\kappa}$ to vary freely they significantly improved model fits at each site. This 'quick fix', however, did not yield better predictions for our data. the greater distance between populations in our study than in that of Alunno-Bruscia et al.

447 (2011) prohibits genetic connectivity, allowing genetic divergence drift and through adaptation to local conditions. This explanation is partly supported at a local scale in Italy by

449 the fact that the model performed better at sites closer to the location where it was first parameterized (Otranto and Gaeta) than those farther away (Ancona and Trieste).

451 However, food availability and SST were similar at Ancona and Trieste in Italy and at Brenton-on-sea and St Francis in South Africa, but, while the model error for Brenton-on-sea was on a par with that for Ancona and Trieste, it was worse at St Francis, suggesting that environmental similarity alone does not explain model skill. 

in parameter values is a fundamental tenet in DEB theory. While DEB models are commonly built for a 'species', the theory maintains that the continuum in parameter values could be followed down to population and individual levels (Nisbet et al. 2000; Kooijman 2010; Sousa et al. 2010). Theoretically then, one could envision different sets of parameter values for different individuals and populations. In practice however, this is not feasible for realistic ecological application, and parameterizations are typically conducted to the species level. The underlying mechanisms that orchestrate phenotypic plasticity and local adaptation at the genome level are complex and still poorly understood in many model species. While flexibility in traits or parameter values due to existing genetic variance can be exposed experimentally (Lesser et al. 2010; Pespeni et al. 2013), plastic responses may not be obvious unless properly tested. Context dependence can complicate the issue to the point that it is impossible to recommend general solutions. Instead, we suggest that a better approach is to expend the necessary effort in identifying the traits that drive poor performance of the model. For instance, because feeding in bivalves depends on several behavioural and physiological responses (filtration efficiency, particle selection, assimilation

471 efficiency) that vary with the environment (Bayne et al. 1993), some DEB models have 472 suggested explicitly incorporating them in models to widen their spatial application (Alunno473 Bruscia et al. 2011; Saraiva et al. 2011; Lavaud et al. 2014). Fine-tuning of model

474 parameters appears to be the only way to maintain the mechanistic nature of this approach.

475 Alternatively, one may re-parameterize the model using locally collected data, but this 476 implies ignoring the processes driving differences between regions, therefore incurring 477 similar drawbacks to those of correlative models (Buckley 2008). 


\section{Conclusions and future directions}

480 Mechanistic models hold great potential for anticipating species physiological and ecological

481 performance across increasingly large spatial scales (Kearney and Porter 2004). However,

482 when working with cosmopolitan species at global scales, notably invasive generalists,

483 ecologists must test the assumption of model stationarity. This study reveals that spatial

484 stationarity cannot be assumed in a Dynamic Energy Budget model built for Mytilus

485 galloprovincialis, and non-stationarity should thus be embraced. The reasons behind a

486 model's failure can be categorized as either 'unaccounted environmental or biological

487 drivers' or as 'genetics'. Unfortunately, the two cannot be separated with our data.

488 Optimal use of DEB models across global scales should address this question by conducting

489 tailored experiments. Furthermore, explicit consideration of the relevant factors that vary

490 amongst populations requires moving beyond the standard DEB model used here to more

491 specialized formulations (Kooijman 2010).

492 Physiological ecologists have warned about the dangers of predicting species

493 distributions in the future based on habitat conditions experienced by populations today

494 (i.e. a 'climate envelope' approach). Although climate envelope models may accurately

495 predict responses under conditions within the realized niche of a species, they perform

496 poorly in scenarios that lie outside of the envelope (Kearney 2006). Therefore, unless

497 corrected, these models inherently assume stationarity in parameter values (Kupfer and

498 Farris 2007; Hothorn et al. 2011). Because mechanistic models aim at describing a species'

499 fundamental niche, they could be considered safe from this problem. However, as we have

500 shown, when used across large geographical scales, mechanistic models can also provide

501 flawed predictions. Progress in the critical endeavour of predicting species' responses to 
climate change requires addressing the issues responsible for poor predictive power rather

503 than ignoring them.

504

\section{List of items in the supplementary material}

506 Appendix S1. Mytilus galloprovincialis Dynamic Energy Budget (DEB) parameter values used 507 to perform model simulations.

508 Appendix S2. Linear regression coefficients from relationships between satellite-derived sea 509 surface temperature and in situ measurements (data available in Appendix S5).

510 Appendix S3. Linear regression coefficients from relationship between weather station air

511 temperature (www.weatherunderground.com/weather/api) and in situ measurements

512 taken with aerially exposed "robomussels" (data available in Appendix S6).

513 Appendix S4. Dynamic Energy Budget (DEB) model scrip for Mytilus galloprovincialis.

514 Appendix S5. Satellite-derived sea surface temperature and in situ measurements used to

515 estimate submerged mussel body temperature.

516 Appendix S6. Weather station air temperature and in situ "robomussels" measurements

517 used to estimate aerially exposed mussel body temperature.

518 Appendix S7. Site-specific environmental data used to run the DEB models. Columns are:

519 region, site, local time (SAST or CEST), estimated body temperature in water $\left({ }^{\circ} \mathrm{C}\right)$, estimated 520 body temperature in air $\left({ }^{\circ} \mathrm{C}\right)$, chlorophyll-a concentration $(\mu \mathrm{g} / \mathrm{L})$, tide height $(\mathrm{m})$, and tide

521 flag (1=mussel submerged, $0=$ =mussel exposed to air).

522

523 Conflict of interest. The authors declare that they have no conflict of interest. 
525

526

527

528

529

530

531

532

533

534

535

536

537

538

539

540

541

542

543

544

545

546

547

548

549

Ethical approval. All applicable international, national, and/or institutional guidelines for the care and use of animals were followed.

\section{References}

Alunno-Bruscia M, Bourlès Y, Maurer D, Robert S, Mazurié J, Gangnery A, Goulletquer P, Pouvreau S (2011) A single bio-energetics growth and reproduction model for the oyster Crassostrea gigas in six Atlantic ecosystems. J Sea Res 66: 340-348 doi 10.1016/j.seares.2011.07.008

Anestis A, Lazou A, Pörtner HO, Michaelidis B (2007) Behavioral, metabolic, and molecular stress responses of marine bivalve Mytilus galloprovincialis during long-term acclimation at increasing ambient temperature. American Journal of Physiology - Regulatory, Integrative and Comparative Physiology 293: R911R921 doi 10.1152/ajpregu.00124.2007

Bayne BL, Iglesias JIP, Hawkins AJS, Navarro E, Heral M, Deslous-Paoli JM (1993) Feeding behaviour of the mussel, Mytilus edulis: responses to variations in quantity and organic content of the seston. J Mar Biol Assoc UK 73: 813-829 doi doi:10.1017/S0025315400034743

Branch GM (1981) The biology of limpets: physical factors, energy flow, and ecological interactions Oceanography and Marine Biology: An Annual Review. Aberdeen University Press/Allen \& Unwin, London, pp 235-380

Brown PC (1992) Spatial and seasonal variation in chlorophyll distribution in the upper $30 \mathrm{~m}$ of the photic zone in the southern Benguela/Agulhas ecosystem. S Afr J Mar Sci 12: 515-525 doi 10.2989/02577619209504722

Buckley LB (2008) Linking traits to energetics and population dynamics to predict lizard ranges in changing environments. Am Nat 171: E1-E19 
550

551

552

553

554

555

556

557

558

559

560

561

562

563

564

565

566

567

568

569

570

571

572

573

Buckley LB (2013) Get real: putting models of climate change and species interactions in practice. Ann N Y Acad Sci 1297: 126-138 doi 10.1111/nyas.12175

Bustamante RH, Branch GM, Eekhout S, Robertson B, Zoutendyk P, Schleyer M, Dye A, Hanekom N, Keats D, Jurd M, McQuaid C (1995) Gradients of intertidal primary productivity around the coast of South Africa and their relationships with consumer biomass. Oecologia 102: 189-201 doi 10.2307/4220948

Carrington E (2002) The ecomechanics of mussel attachment: from molecules to ecosystems. Integr Comp Biol 42: 846-852

Colella S, Falcini F, Rinaldi E, Sammartino M, Santoleri R (2016) Mediterranean Ocean Colour chlorophyll trends. PLoS One 11: e0155756 doi 10.1371/journal.pone.0155756

Demarcq H, Barlow RG, Shillington FA (2003) Climatology and variability of sea surface temperature and surface chlorophyll in the Benguela and Agulhas ecosystems as observed by satellite imagery. Afr J Mar Sci 25: 363-372 doi $10.2989 / 18142320309504022$

Denny M, Helmuth B (2009) Confronting the physiological bottleneck: a challenge from ecomechanics. Integr Comp Biol 49: 197-201 doi 10.1093/icb/icp070

Gilman SE (2017) Predicting indirect effects of predator-prey interactions. Integr Comp Biol icx031 doi doi.org/10.1093/icb/icx031

Grant BW, Porter WP (1992) Modeling global macroclimatic constraints on ectotherm energy budgets. Am Zool 32: 154-178 doi 10.1093/icb/32.2.154

Harley CDG, Helmuth BST (2003) Local- and regional-scale effects of wave exposure, thermal stress, and absolute versus effective shore level on patterns of intertidal zonation. Limnol Oceanogr 48: 1498-1508 
Helmuth B, Choi F, Matzelle A, Torossian JL, Morello SL, Mislan KAS, Yamane L, Strickland D, Szathmary PL, Gilman SE, Tockstein A, Hilbish TJ, Burrows MT, Power AM, Gosling E, Mieszkowska N, Harley CDG, Nishizaki M, Carrington E, Menge B, Petes L, Foley MM, Johnson A, Poole M, Noble MM, Richmond EL, Robart M, Robinson J, Sapp J, Sones J, Broitman BR, Denny MW, Mach KJ, Miller LP, O’Donnell M, Ross P, Hofmann GE, Zippay M, Blanchette C, Macfarlan JA, Carpizo-Ituarte E, Ruttenberg B, Peña Mejía CE, McQuaid CD, Lathlean J, Monaco CJ, Nicastro KR, Zardi G (2016) Long-term, high frequency in situ measurements of intertidal mussel bed temperatures using biomimetic sensors. Scientific Data 3: 160087 doi 10.1038/sdata.2016.87

Helmuth BST (1998) Intertidal mussel microclimates: predicting the body temperature of a sessile invertebrate. Ecol Monogr 68: 51-74

Hijmans RJ (2016) raster: Geographic Data Analysis and Modeling. R package version 2.5-8. https://CRAN.R-project.org/package=raster

Hochachka PW, Somero GN (2002) Biochemical Adaptation: Mechanism and Process in Physiological Evolution. Oxford University Press, New York

Hofmann GE, Gaines SD (2008) New tools to meet new challenges: emerging technologies for managing marine ecosystems for resilience. Bioscience 58: 4352 doi 10.1641/B580109

Hölker F, Mehner T (2005) Simulation of trait- and density-mediated indirect effects induced by piscivorous predators. Basic Appl Ecol 6: 289-300 doi doi.org/10.1016/j.baae.2004.10.001

Holling CS (1959) Some characteristics of simple types of predation and parasitism. Can Entomol 91: 385-398 
Hothorn T, Müller J, Schröder B, Kneib T, Brandl R (2011) Decomposing environmental, spatial, and spatiotemporal components of species distributions. Ecol Monogr 81: 329-347 doi 10.1890/10-0602.1

Izaguirre C, Méndez FJ, Menéndez M, Losada IJ (2011) Global extreme wave height variability based on satellite data. Geophys Res Lett 38 doi 10.1029/2011GL047302

Jimenez AG, Alves S, Dallmer J, Njoo E, Roa S, Dowd WW (2016) Acclimation to elevated emersion temperature has no effect on susceptibility to acute, heat-induced lipid peroxidation in an intertidal mussel (Mytilus californianus). Mar Biol 163: 55 doi $10.1007 / \mathrm{s} 00227-016-2828-8$

Kaehler S, McQuaid CD (1999) Use of the fluorochrome calcein as an in situ growth marker in the brown mussel Perna perna. Mar Biol 133: 455-460 doi $10.1007 / \mathrm{s} 002270050485$

Karasov WH, Martínez del Rio C (2007) Physiological Ecology: How Animals Process Energy, Nutrients, and Toxins. Princeton University Press, Princeton

Kearney M (2006) Habitat, environment and niche: what are we modelling? Oikos 115: 186-191 doi 10.1111/j.2006.0030-1299.14908.x

Kearney M, Porter WP (2004) Mapping the fundamental niche: physiology, climate, and the distribution of a nocturnal lizard. Ecology 85: 3119-3131

Kerr JT, Ostrovsky M (2003) From space to species: ecological applications for remote sensing. Trends Ecol Evol 18: 299-305 doi 10.1016/S0169-5347(03)00071-5

Kitazawa D, Tabeta S, Kato T, Ruardij P (2008) A comparative study of the biomassbased and individual-based models of blue mussels. Ecol Modell 215: 93-104 doi 10.1016/j.ecolmodel.2008.02.014 
622 Klok C, Wijsman JWM, Kaag K, Foekema E (2014) Effects of CO2 enrichment on cockle

623

624

625

626

627

628

629

630

631

632

633

634

635

636

637

638

639

640

641

642

643

644

645

646 shell growth interpreted with a Dynamic Energy Budget model. J Sea Res 94: 111-116 doi 10.1016/j.seares.2014.01.011

Kooijman SALM (2010) Dynamic Energy Budget Theory For Metabolic Organization. Cambridge University Press, Cambridge

Kupfer J, Farris C (2007) Incorporating spatial non-stationarity of regression coefficients into predictive vegetation models. Landsc Ecol 22: 837-852

Lathlean JA, Ayre DJ, Minchinton TE (2011) Rocky intertidal temperature variability along the southeast coast of Australia: comparing data from in situ loggers, satellite-derived SST and terrestrial weather stations. Mar Ecol Prog Ser 439: 8395

Lavaud R, Flye-Sainte-Marie J, Jean F, Emmery A, Strand Ø, Kooijman SALM (2014) Feeding and energetics of the great scallop, Pecten maximus, through a DEB model. J Sea Res 94: 5-18 doi 10.1016/j.seares.2013.10.011

Lesser MP (2016) Climate change stressors cause metabolic depression in the blue mussel, Mytilus edulis, from the Gulf of Maine. Limnol Oceanogr 61: 1705-1717 doi 10.1002/lno.10326

Lesser MP, Bailey MA, Merselis DG, Morrison JR (2010) Physiological response of the blue mussel Mytilus edulis to differences in food and temperature in the Gulf of Maine. Comparative Biochemistry and Physiology - Part A: Molecular \& Integrative Physiology 156: 541-551

Mancuso SG, Morgan VA, Mitchell PB, Berk M, Young A, Castle DJ (2015) A comparison of schizophrenia, schizoaffective disorder, and bipolar disorder: results from the second Australian national psychosis survey. J Affect Disord 172: 30-37 doi 10.1016/j.jad.2014.09.035 
Marquet N, Nicastro KR, Gektidis M, McQuaid CD, Pearson GA, Serrão EA, Zardi GI (2013) Comparison of phototrophic shell-degrading endoliths in invasive and native populations of the intertidal mussel Mytilus galloprovincialis. Biol Invasions 15: 1253-1272 doi 10.1007/s10530-012-0363-1

McQuaid CD, Lindsay TL (2000) Effect of wave exposure on growth and mortality rates of the mussel Perna perna: bottom up regulation of intertidal populations. Mar Ecol Prog Ser 206: 147-154 doi 10.3354/meps206147

Monaco CJ, Helmuth B (2011) Tipping points, thresholds and the keystone role of physiology in marine climate change research. Adv Mar Biol 60: 124-154

Monaco CJ, McQuaid CD (2018) Applicability of Dynamic Energy Budget (DEB) models across steep environmental gradients. Sci Rep 8: 16384 doi 10.1038/s41598018-34786-w

Monaco CJ, Wethey DS, Helmuth B (2014) A dynamic energy budget (DEB) model for the keystone predator Pisaster ochraceus. PLoS One 9: e104658 doi 10.1371/journal.pone.0104658

Montalto V, Rinaldi A, Sarà G (2015) Life history traits to predict biogeographic species distributions in bivalves. Sci Nat 102: 1-12 doi 10.1007/s00114-015-1313-4

Nicastro KR, Zardi GI, McQuaid CD (2010) Differential reproductive investment, attachment strength and mortality of invasive and indigenous mussels across heterogeneous environments. Biol Invasions 12: 2165-2177 doi 10.1007/s10530-009-9619-9

Nisbet RM, Muller EB, Lika K, Kooijman SALM (2000) From molecules to ecosystems through dynamic energy budget models. J Anim Ecol 69: 913-926

Peharda M, Ezgeta-Balić D, Radman M, Sinjkević N, Vrgoč N, Isajlović I (2011) Age, growth and population structure of Acanthocardia tuberculata (Bivalvia: 
672

673

674

675

676

677

678

679

680

681

682

683

684

685

686

687

688

689

690

691

692

693

694

695

696

Cardiidae) in the eastern Adriatic Sea. Sci Mar 76: 59-66 doi 10.3989/scimar.03257.21A

Pespeni MH, Sanford E, Gaylord B, Hill TM, Hosfelt JD, Jaris HK, LaVigne M, Lenz EA, Russell AD, Young MK, Palumbi SR (2013) Evolutionary change during experimental ocean acidification. Proc Natl Acad Sci 110: 6937-6942 doi $10.1073 /$ pnas. 1220673110

Pierce D (2015) ncdf4: Interface to Unidata netCDF (Version 4 or Earlier) Format Data Files. R package version 1.15. https://CRAN.R-project.org/package=ncdf4

Pincebourde S, Woods HA (2012) Climate uncertainty on leaf surfaces: the biophysics of leaf microclimates and their consequences for leaf-dwelling organisms. Funct Ecol 26: 844-853 doi 10.1111/j.1365-2435.2012.02013.x

Potter KA, Woods HA, Pincebourde S (2013) Microclimatic challenges in global change biology. Glob Chang Biol 19: 2932-2939 doi 10.1111/gcb.12257

R Core Team (2016) R: A Language and Environment for Statistical Computing. R Foundation for Statistical Computing, Vienna, Austria

Sanford E, Kelly MW (2011) Local adaptation in marine invertebrates. Annual Review of Marine Science 3: 509-535 doi 10.1146/annurev-marine-120709-142756

Sarà G, Kearney M, Helmuth B (2011) Combining heat-transfer and energy budget models to predict thermal stress in Mediterranean intertidal mussels. Chem Ecol 27: $135-145$ doi 10.1080/02757540.2011.552227

Sarà G, Palmeri V, Montalto V, Rinaldi A, Widdows J (2013) Parameterisation of bivalve functional traits for mechanistic eco-physiological dynamic energy budget (DEB) models. Mar Ecol Prog Ser 480: 99-117 doi 10.3354/meps10195

Sarà G, Reid G, Rinaldi A, Palmeri V, Troell M, Kooijman S (2012) Growth and reproductive simulation of candidate shellfish species at fish cages in the 
697

698

699

700

701

702

703

704

705

706

707

708

709

710

711

712

713

714

715

716

717

718

719

Southern Mediterranean: Dynamic Energy Budget (DEB) modelling for integrated multi-trophic aquaculture. Aquaculture 324: 259 - 266

Saraiva S, van der Meer J, Kooijman SALM, Sousa T (2011) Modelling feeding processes in bivalves: a mechanistic approach. Ecol Modell 222: 514-523 doi 10.1016/j.ecolmodel.2010.09.031

Saulquin B, Gohin F, Garrello R (2011) Regional objective analysis for merging highresolution MERIS, MODIS/Aqua, and SeaWiFS Chlorophyll- $a$ data from 1998 to 2008 on the European Atlantic shelf. IEEE Transactions on Geoscience and Remote Sensing 49: 143-154

Seebens H, Blackburn TM, Dyer EE, Genovesi P, Hulme PE, Jeschke JM, Pagad S, Pyšek P, Winter M, Arianoutsou M, Bacher S, Blasius B, Brundu G, Capinha C, CelestiGrapow L, Dawson W, Dullinger S, Fuentes N, Jäger H, Kartesz J, Kenis M, Kreft H, Kühn I, Lenzner B, Liebhold A, Mosena A, Moser D, Nishino M, Pearman D, Pergl J, Rabitsch W, Rojas-Sandoval J, Roques A, Rorke S, Rossinelli S, Roy HE, Scalera R, Schindler S, Štajerová K, Tokarska-Guzik B, van Kleunen M, Walker K, Weigelt P, Yamanaka T, Essl F (2017) No saturation in the accumulation of alien species worldwide. Nature Communications 8: 14435 doi 10.1038/ncomms14435

Sinervo B, Adolph SC (1994) Growth plasticity and thermal opportunity in Sceloporus lizards. Ecology 75: 776-790 doi 10.2307/1941734

Smit AJ, Roberts M, Anderson RJ, Dufois F, Dudley SFJ, Bornman TG, Olbers J, Bolton JJ (2013) A coastal seawater temperature dataset for biogeographical studies: large biases between in situ and remotely-sensed data sets around the coast of South Africa. PLoS One 8: e81944 doi 10.1371/journal.pone.0081944 
Sokolova IM (2013) Energy-limited tolerance to stress as a conceptual framework to integrate the effects of multiple stressors. Integr Comp Biol 53: 597-608 doi 10.1093/icb/ict028

Sousa T, Domingos T, Poggiale J-C, Kooijman SALM (2010) Dynamic energy budget theory restores coherence in biology. Philosophical Transactions of the Royal Society B: Biological Sciences 365: 3413-3428 doi 10.1098/rstb.2010.0166

Stenseth N, Ottersen G, Hurrell J, Mysterud A, Lima M, Chan K-S, Yoccoz N, Adlandsvik B (2003) Studying climate effects on ecology through the use of climate indices: the North Atlantic Oscillation, El Nino Southern Oscillation and beyond. Proc R Soc Lond B 270: 2087 - 2096

Tagliarolo M, McQuaid C (2015) Sub-lethal and sub-specific temperature effects are better predictors of mussel distribution than thermal tolerance. Mar Ecol Prog Ser 535: 145-159 doi 10.3354/meps11434

Tagliarolo M, Montalto V, Sarà G, Lathlean JA, McQuaid CD (2016) Low temperature trumps high food availability to determine the distribution of intertidal mussels Perna perna in South Africa. Mar Ecol Prog Ser 558: 51-63

Valladares F, Matesanz S, Guilhaumon F, Araújo MB, Balaguer L, Benito-Garzón M, Cornwell W, Gianoli E, Kleunen M, Naya DE (2014) The effects of phenotypic plasticity and local adaptation on forecasts of species range shifts under climate change. Ecol Lett 17: 1351-1364

van der Meer J, Klok C, Kearney MR, Wijsman JWM, Kooijman SALM (2014) 35 years of DEB research. J Sea Res 94: 1-4 doi 10.1016/j.seares.2014.09.004

Walther GR, Post E, Convey P, Menzel A, Parmesan C, Beebee TJC, Fromentin JM, HoeghGuldberg O, Bairlein F (2002) Ecological responses to recent climate change. Nature 416: 389-395 
745 Widdows J, Johnson D (1988) Physiological energetics of Mytilus edulis: Scope for Growth. Mar Ecol Prog Ser 46: 113-121

747 Wilcox RR (2012) Introduction to robust estimation and hypothesis testing.

$748 \quad$ Elsevier/Academic Press, Amsterdam

749 Woodin SA, Hilbish TJ, Helmuth B, Jones SJ, Wethey DS (2013) Climate change, species

750 distribution models, and physiological performance metrics: predicting when

751 biogeographic models are likely to fail. Ecol Evol 3: 3334-3346 doi

752 $10.1002 /$ ece 3.680

753 Zardi GI, McQuaid CD, Nicastro KR (2007) Balancing survival and reproduction:

754 seasonality of wave action, attachment strength and reproductive output in indigenous Perna perna and invasive Mytilus galloprovincialis mussels. Mar Ecol Prog Ser 334: 155-163 doi 10.3354/meps334155

757 
759 Table 1. Error statistics $(\mathrm{RMSE}=$ Root Mean Square Error, $\mathrm{MAE}=$ Mean Absolute Error) to

760 compare Dynamic Energy Budget model mussel shell length (g) predictions against

761 observations of size at age. The number $(N)$ of individuals aged as 1 and 2 years old is

762 provided.

\begin{tabular}{|c|c|c|c|c|c|}
\hline Region/Site & $\mathbf{N}$ age 1 & $\mathbf{N}$ age 2 & Total N & RMSE (g) & MAE (g) \\
\hline \multicolumn{6}{|c|}{ Mediterranean Sea } \\
\hline Gaeta & 93 & 4 & 97 & 0.014 & 0.012 \\
\hline Otranto & 153 & 21 & 174 & 0.039 & 0.035 \\
\hline Ancona & 44 & 47 & 91 & 0.188 & 0.140 \\
\hline Trieste & 88 & 12 & 100 & 0.197 & 0.152 \\
\hline Total N & 378 & 84 & 462 & & \\
\hline \multicolumn{6}{|l|}{ South Africa } \\
\hline Hondeklip Bay & 2 & 25 & 27 & 0.958 & 0.930 \\
\hline Paternoster & 31 & 78 & 109 & 0.698 & 0.608 \\
\hline Brenton-on-sea & 4 & 9 & 13 & 0.286 & 0.234 \\
\hline St. Francis & 40 & 68 & 108 & 0.923 & 0.780 \\
\hline Total N & 77 & 180 & 257 & & \\
\hline
\end{tabular}


765 Table 2. Bootstrapped one-way ANOVA results testing the effect of region (Mediterranean

766 Sea vs. South African coast) on Mytilus galloprovincialis DEB model skill (absolute error).

\begin{tabular}{llllll}
\hline Source & SS & df & F & $95 \% \mathbf{C l}$ & $\mathbf{p}$ \\
\hline Region & 64.69 & 1 & 987.35 & $782.16-1236.35$ & $<0.001$ \\
Residuals & 53.53 & 817 & & & \\
\hline
\end{tabular}

767

768 
770 Fig. 1 Maps illustrating the geographical extent covered by this study and that which

771 resulted on the original parameterization of the Dynamic Energy Budget model used here

772 (Sarà et al. 2012). (A) Global scale showing a portion of Europe and Africa. The countries

773 sampled, Italy and South Africa, are indicated in grey. The main bodies of water influencing

774 our sampled mussels are also provided (M.S. = Mediterranean Sea). The sampled populations in the Mediterranean Sea region are shown in (B), and those from the South African region in (C). Our study sites are represented by circles, while that used by Sarà et al. (2012) is indicated by a star. Maps produced using SimpleMappr (http://www.simplemappr.net).

Fig. 2 Dynamic Energy Budget model soma dry weight (g) growth simulations for 1 (grey) and 2 (black) year old Mytilus galloprovincialis (using original parameter values and local environmental conditions). Observations of size-at-age are illustrated by circles and crosses for 1 and 2-year-old mussels, respectively. The symbols are slightly offset to prevent cluttering. The scale differs between panels. Panels (A)-(D) correspond to Mediterranean Sea populations, and (E)-(H) South African populations.

Fig. 3 Absolute errors calculated from Dynamic Energy Budget model simulations vs. observed growth for each site (see Fig. 2). Data are separated by region: native populations

787 from the Mediterranean Sea in grey $(G A=$ Gaeta, OTRA = Otranto, $A N C O=$ Ancona, $T R I=$ 788 Trieste) and non-native South African populations (HB = Hondeklip Bay, PA = Paternoster, BR $=$ Brenton-on-sea, $\mathrm{SF}=$ St. Francis) in white. The violin shapes represent distribution densities. The white circles are the medians. The boxes are the $25^{\text {th }}$ and $75^{\text {th }}$ percentiles of the distribution. The lines extending vertically are maximally 1.5 times the interquartile 
792 range. Different letters above the violins reflect significant differences between sites 793 (bootstrapped ANOVA, post hoc pairwise comparison with Bonferroni correction).

794 Fig. 4 Environmental conditions, (A) chlorophyll-a, (B) submerged body temperature, and 795 (C) aerial body temperature experienced by mussel populations at each site over a period of 7962 years. Data are given in violin plots and separated by region as in Fig. 3 . Correlations 797 between Mean Absolute Error (MAE) and mean environmental variables (D) chlorophyll-a 798 concentration, (E) submerged body temperature, and (F) aerial body temperature. 
Fig. 1

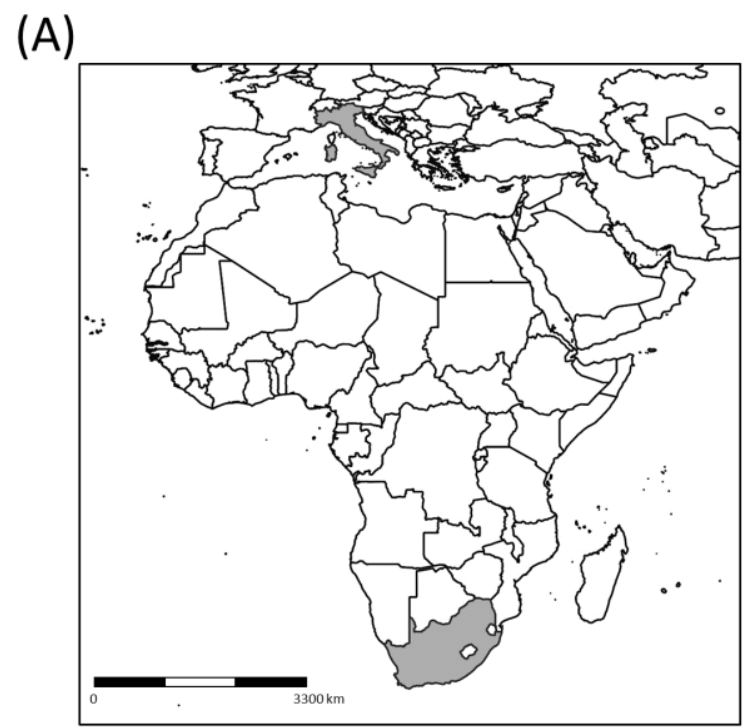

(B)

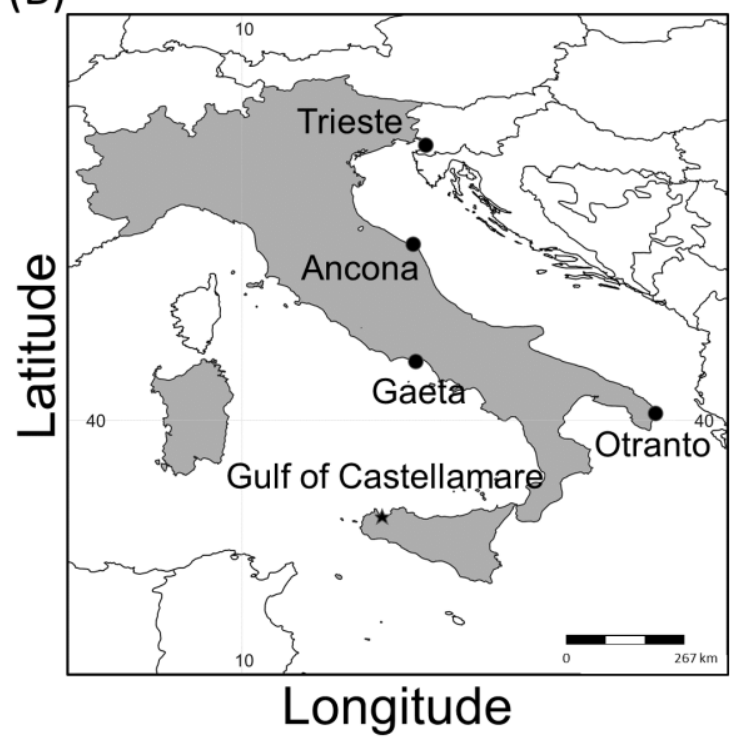

(C)

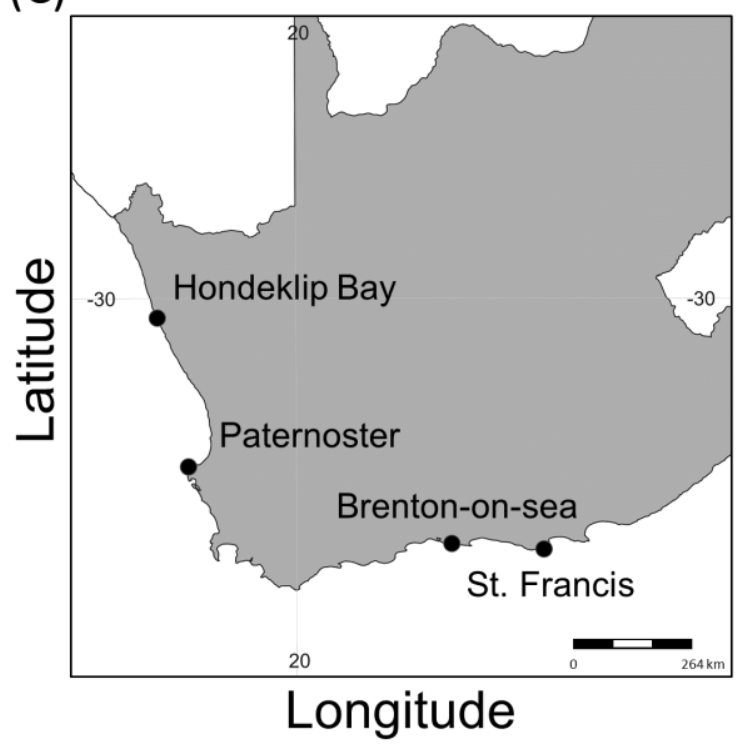


$803 \quad$ Fig. 2
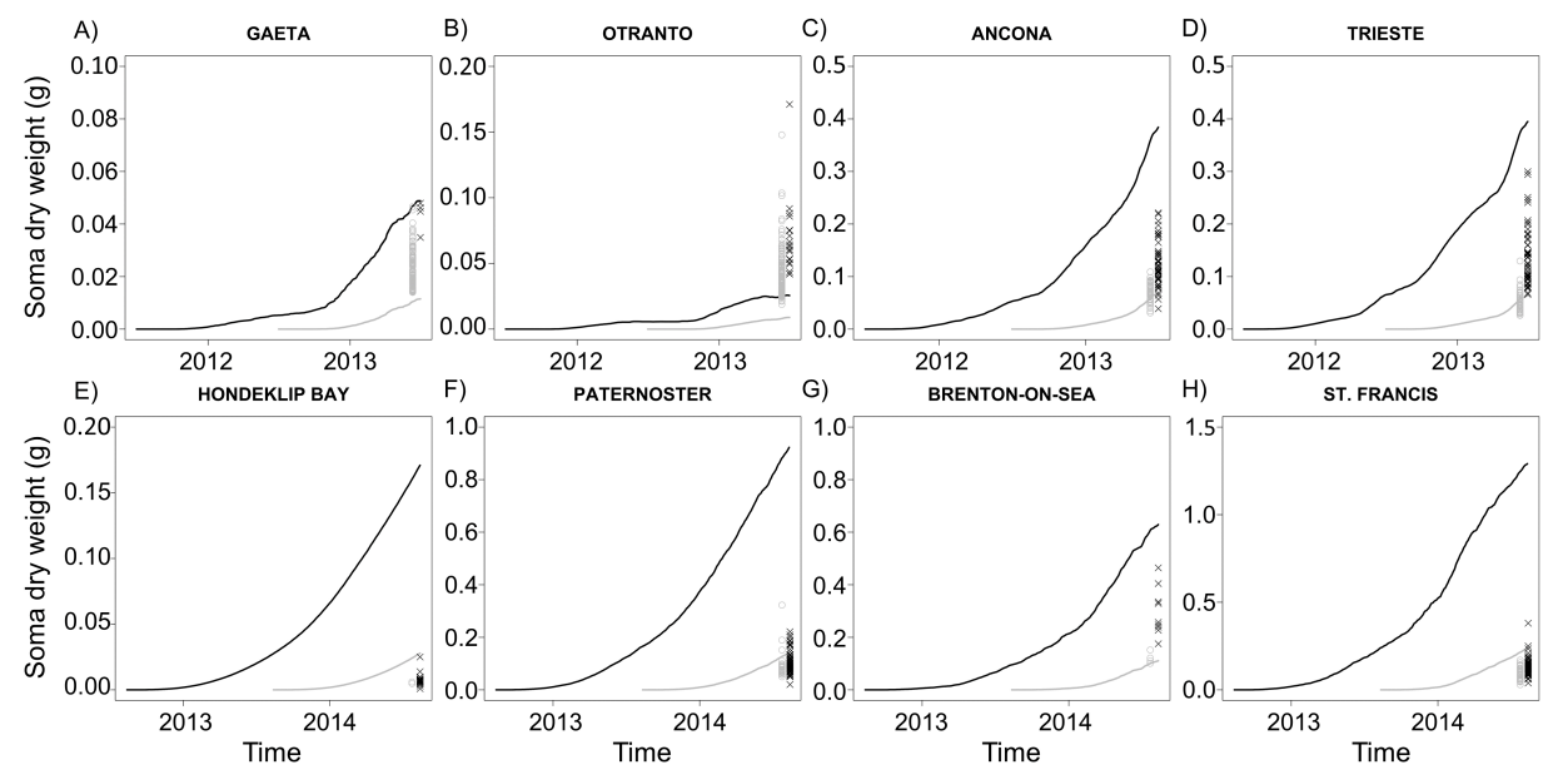
Fig. 3

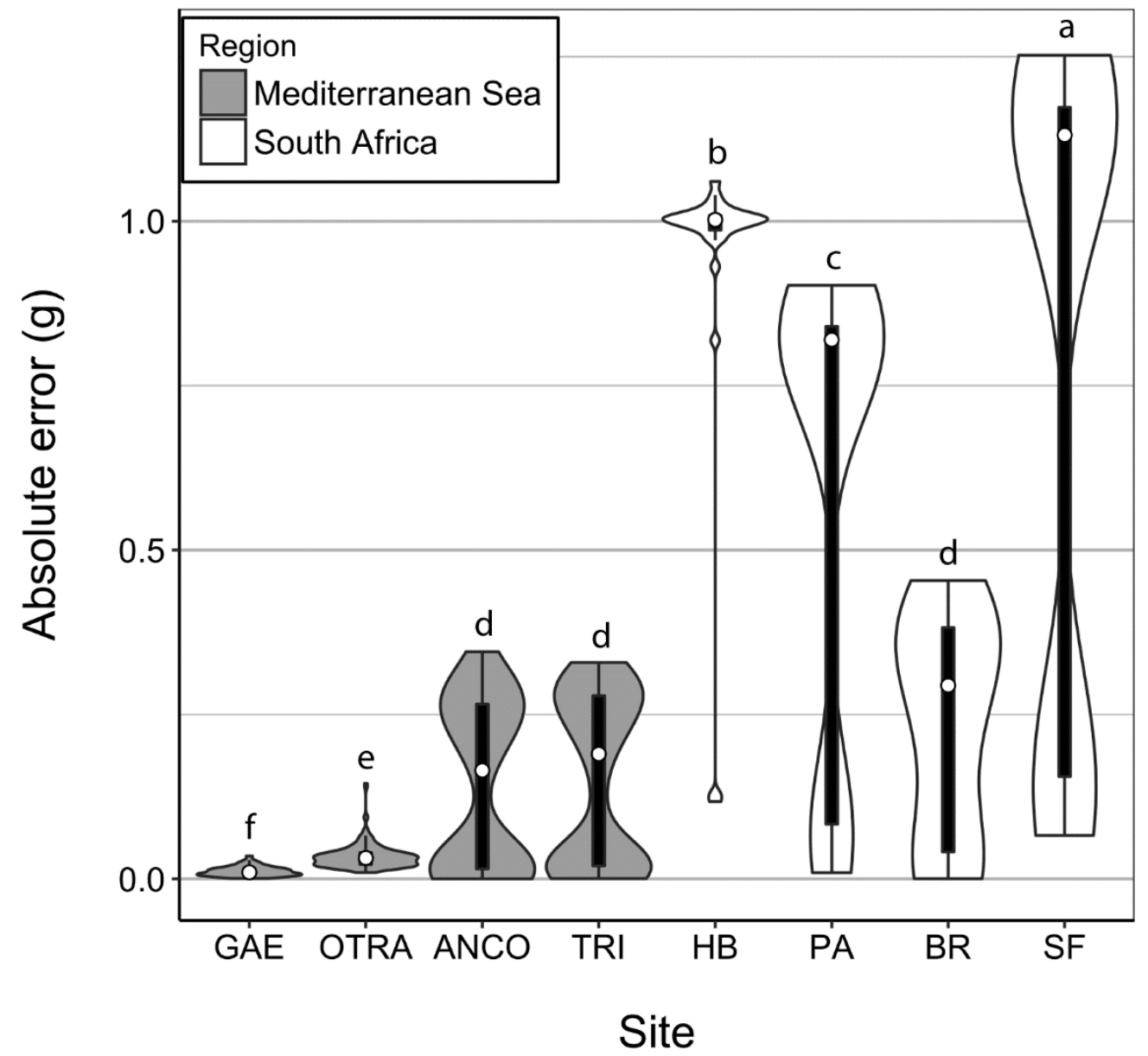

807 
Fig. 4

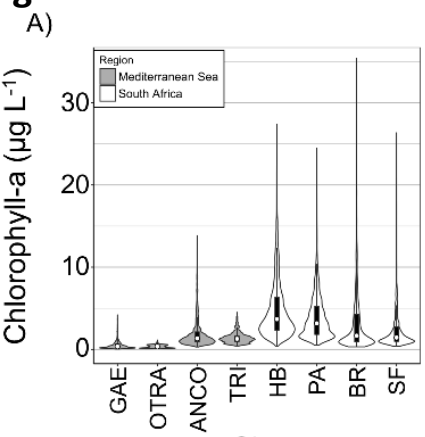

D)

Site

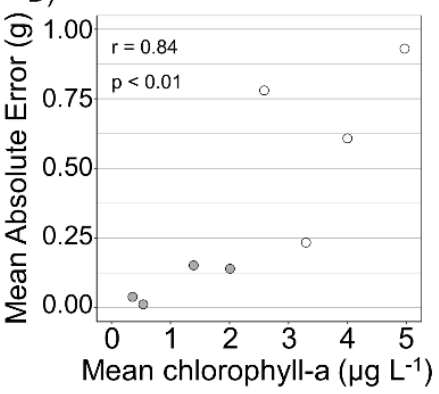

810
B)

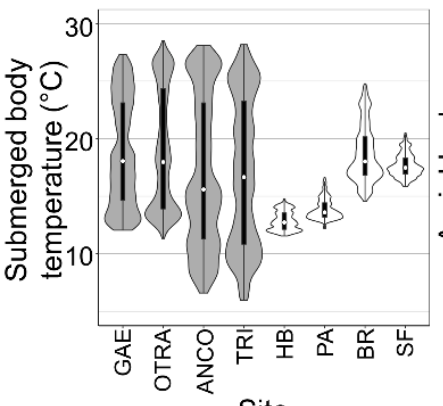

E)

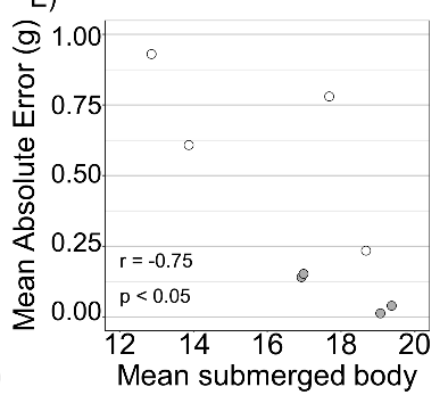
temperature $\left({ }^{\circ} \mathrm{C}\right)$
C)
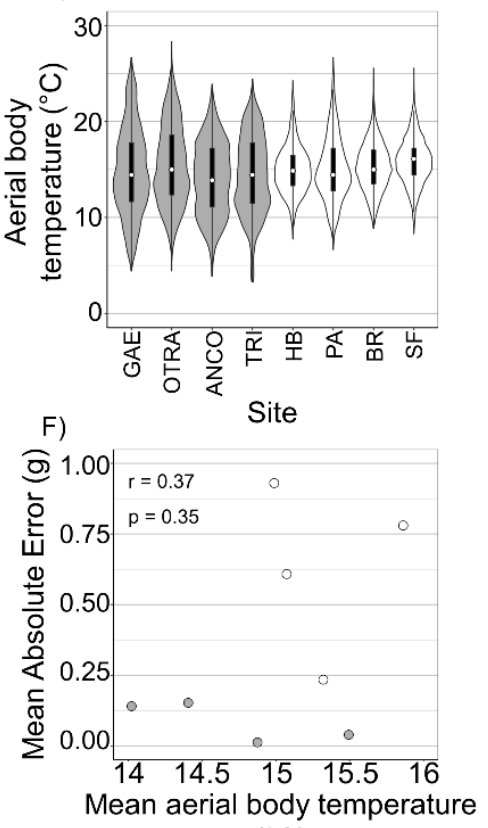

$\left({ }^{\circ} \mathrm{C}\right)$ 